\title{
Article
}

\section{Structure and Reactivity of a Model Oxide Supported Silver Nanocluster Catalyst Studied by Near Ambient Pressure X-ray Photoelectron Spectroscopy}

Wagstaffe, Michael, Hussain, Hadeel, Acres, Matthew, Jones, Rosemary, Syres, Karen and Thomas, Andrew G.

Available at https://clok.uclan.ac.uk/19909/

Wagstaffe, Michael, Hussain, Hadeel, Acres, Matthew, Jones, Rosemary, Syres, Karen orcid iconORCID: 0000-0001-7439-475X and Thomas, Andrew G. (2017) Structure and Reactivity of a Model Oxide Supported Silver Nanocluster Catalyst Studied by Near Ambient Pressure X-ray Photoelectron Spectroscopy. The Journal of Physical Chemistry C, 121 (39). pp. 21383-21389. ISSN 19327447

It is advisable to refer to the publisher's version if you intend to cite from the work. http://dx.doi.org/10.1021/acs.jpcc.7b05818

For more information about UCLan's research in this area go to http://www.uclan.ac.uk/researchgroups/ and search for <name of research Group>.

For information about Research generally at UCLan please go to http://www.uclan.ac.uk/research/

All outputs in CLoK are protected by Intellectual Property Rights law, including Copyright law. Copyright, IPR and Moral Rights for the works on this site are retained by the individual authors and/or other copyright owners. Terms and conditions for use of this material are defined in the policies page. 


\section{Structure and Reactivity of a Model Oxide Supported Silver Nanocluster Catalyst Studied by Near Ambient Pressure X-ray Photoelectron Spectroscopy}

Michael Wagstaffe, ${ }^{\dagger}$ Hadeel Hussain, ${ }^{\ddagger}$ Matthew Acres, ${ }^{\ddagger}$ Rosemary Jones, ${ }^{\S}$ Karen

L. Syres, ${ }^{*}$ and Andrew G. Thomas ${ }^{*} \neq \S$

${ }^{\dagger}$ School of Physics and Astronomy, The University of Manchester, Oxford Road, M13 9PL, UK.

${ }^{\ddagger}$ School of Materials, The University of Manchester, Sackville Street, Manchester, M13 9PL, UK.

$\S$ Photon Science Institute, The University of Manchester, Oxford Road, Manchester, M13 9PL, UK .

ף Jeremiah Horrocks Institute, The University of Central Lancashire, Fylde Road, Preston, PR1 2HE, UK.

@Current address: Diamond Light Source, Harwell Science and Innovation Campus, Didcot, Oxfordshire, OX11 ODE, UK.

E-mail: andrew.g.thomas@manchester.ac.uk, ksyres@uclan.ac.uk 


\section{Abstract}

The photocatalytic activity of anatase $\mathrm{TiO}_{2}$ decorated with metal clusters has been widely documented, but the nature of the metal-metal oxide interface and reaction intermediates in catalytic processes are still not well understood. This in part is due to the fact that use of photoelectron spectroscopy to deduce the surface chemistry of catalytic systems has long been hampered by the huge pressure difference between real-world operation and the requirement of high vacuum for electron detection. Here, the in situ growth of silver nanoparticles on a model metal-oxide catalyst support and their reactivity with a $\mathrm{CO} / \mathrm{H}_{2} \mathrm{O}$ gas mixture has been investigated in detail. Using synchrotron X-ray photoelectron spectroscopy, nearambient pressure X-ray photoelectron spectroscopy and scanning tunneling microscopy, the interaction of $\mathrm{Ag}$ with the anatase $\mathrm{TiO}_{2}$ surface leads to metalsurface charge transfer and low mobility of $\mathrm{Ag}$ on the surface. Upon exposure to a 1.5 mbar $\mathrm{CO} / 1.5$ mbar $\mathrm{H}_{2} \mathrm{O}$ gas mixture, partial oxidation of the Ag clusters is observed. There is also evidence suggesting that a Ag-carbonyl species is formed during exposure of the $\mathrm{Ag} / \mathrm{TiO}_{2}$ surface to a $\mathrm{CO} / \mathrm{H}_{2} \mathrm{O}$ gas mixture. 


\section{Introduction}

Metal clusters supported on well-ordered metal oxide surfaces are of great interest due to their application in a wide variety of fields, including photovoltaics, photocatalysis and transition metal catalysis. ${ }^{1-6}$ Carbon monoxide (CO), in particular, is a major air pollutant which causes serious environmental and health concerns. As such the catalytic oxidation of $\mathrm{CO}$, to form $\mathrm{CO}_{2}$, is an important research area. ${ }^{7-9}$ Noble metals supported on metal oxide ceramic supports have long been used for the catalytic conversion of $\mathrm{CO}$ to $\mathrm{CO}_{2}$, but the high cost of these metals remains a major issue. Noble metal clusters on oxide substrates are also of interest since they can produce high Schottky barriers which facilitate the capture of electrons. ${ }^{10}$ As a result, such systems have been widely investigated, both experimentally and theoretically $5^{5,11-19}$ as potential photocatalytic materials which rely on rapid separation of photogenerated electrons and holes. The structural, chemical and electronic properties at the interface between the metal clusters and the oxide support have all been shown to have a strong influence on catalytic and photocatalytic activity. ${ }^{1,2,6,8,17-24}$

$\mathrm{TiO}_{2}$ is an extremely versatile metal oxide: it is abundant, has low manufacturing costs, is chemically stable and is both non- toxic and highly resistant to corrosion. The anatase polymorph of $\mathrm{TiO}_{2}$ is widely used in catalysis due to its high photocatalytic activity, with the (101) facet being the most thermodynamically stable. ${ }^{25}$ Often rutile and anatase $\mathrm{TiO}_{2}$ powders are mixed, as in $\mathrm{P} 25,{ }^{26}$ which increases the catalytic activity further due to the slight differences in the band gap energies of the two polymorphs. Ag is also non-toxic, catalytically active and has the 
highest thermal and electrical conductivity of all the noble metals. ${ }^{27}$ In addition, $\mathrm{Ag}$ is not as costly as other noble metals. ${ }^{9}$ Catalyst systems based on $\mathrm{Ag} / \mathrm{TiO}_{2}$ have been shown to efficiently catalyze reactions at solid-gas interfaces and in aqueous solutions. They have also been found to substantially enhance the photocatalytic capacity of $\mathrm{TiO}_{2}$ for renewable energy generation and environmental purification. ${ }^{20,28}$ Density Functional Theory (DFT+U) calculations of $\mathrm{O}_{2}$ and $\mathrm{CO}$ activation on the $\mathrm{Ag} /$ anatase $\mathrm{TiO}_{2}$ (101) surface indicated that the atomic and electronic structures of the metal clusters and the synergistic effect of adjacent reactants and oxygen defects on the semiconductor support all have an important role in catalytic $\mathrm{O}_{2}$ activation and $\mathrm{CO}$ oxidation. ${ }^{29}$

Here we present a detailed study of the growth of $\mathrm{Ag}$ clusters deposited on the anatase $\mathrm{TiO}_{2}(101)$ surface. Near-Ambient Pressure X-ray Photoelectron Spectroscopy (NAP-XPS) has developed rapidly over the previous 10 years. The technique allows $\mathrm{X}$ ray Photoemission Spectroscopy (XPS) measurements to be made at pressures of tens of mbars, and has led to the a wealth of publications relevant to catalysis, electrochemistry, material degradation and gas capture for example. ${ }^{30-35}$ NAP-XPS is therefore employed to study the in situ reaction of $\mathrm{H}_{2} \mathrm{O}$ and $\mathrm{CO}$ on an Ag cluster decorated anatase $\mathrm{TiO}_{2}(101)$ surface in order to determine the mechanism of $\mathrm{CO}$ oxidation.

\section{Experimental Method}

UHV synchrotron photoelectron spectroscopy was carried out on the bending magnet soft X-ray beamline, D1011 (photon energy range $30 \mathrm{eV}<h v<1600 \mathrm{eV}$ ) at 
MAX-lab, Sweden. The NAP-XPS system employed in this work is located at The University of Manchester and is equipped with a monochromated Al Ka source ( $h v=$ $1486.6 \mathrm{eV}$ ) and a SPECS $150 \mathrm{~mm}$ Phoibos 150 NAP electron energy analyzer, fitted with a three-stage, differentially pumped electrostatic lens. The $\mathrm{TiO}_{2}(101)$ crystal with $\mathrm{Ag}$ nanoclusters was analyzed at $10^{-9} \mathrm{mbar}$ and under exposure to $3 \mathrm{mbar}^{\mathrm{H}} \mathrm{O}$ and a 1.5 mbar $\mathrm{H}_{2} \mathrm{O} / 1.5$ mbar $\mathrm{CO}$ gas mixture in a high-pressure cell. The $\mathrm{CO}$ gas (99.9995 \%, CK gases) is further purified by means of a scrubber (SAES MicroTorr). Water vapour is produced from doubly distilled water, which is subjected to multiple freeze thaw cycles to remove dissolved gases. All photoelectron spectra are recorded at normal emission with the crystal at room temperature.

The structure and size of the clusters deposited on the $\mathrm{TiO}_{2}(101)$ surface were studied using an Omicron AFM-STM, in a chamber equipped with both Auger electron spectroscopy (AES), and LEED. Sample preparation was carried out in an identical way to the photoemission work. STM data were typically acquired in the constant current mode at sample biases of 1.5-2 V and tunnelling currents 0.1-0.5 nA. Image processing was performed using a combination of Nanotec Electronica WSXM ${ }^{\text {TM36 }}$ and Gwyddion. ${ }^{37}$ For both XPS and STM measurements the anatase $\mathrm{TiO}_{2}(101)$ single crystal ( $5 \mathrm{~mm} \times 5 \mathrm{~mm}$, Pikem Ltd.) was cleaned by repeated $1 \mathrm{keV}$ $\mathrm{Ar}^{+}$ion bombardment and $700^{\circ} \mathrm{C}$ anneal cycles until a sharp $(1 \times 1)$ LEED pattern was obtained and XPS/AES showed the surface to be free of contamination.

For all experimental systems the Ag evaporator consisted of $5 \mu \mathrm{m}$ diameter silver wire (99.99 \%; BDH Chemicals Ltd) wrapped around a tungsten filament and was 
thoroughly degassed prior to use. Ag dosing was carried out at chamber pressures below $10^{-9}$ mbar. Fitting of all core level spectra was carried out using CasaXPS, utilising a Shirley background, Gaussian:Lorentzian curves (0.7:0.3), for non-metallic species, and a modified Gaussian:Lorentzian curve (0.7:0.3), with an asymmetric tail to higher binding energy, for metallic species. ${ }^{38}$ This $0.7: 0.3$, G:L lineshape is widely used in the fitting of photoemission peaks recorded using monochromatic X-rays and produces a good fit to the data. The choice of 70:30 G:L peak shape is empirical and based on the shape which gave the best fit to the data. 


\section{Results and Discussion}

\section{Ag cluster growth on anatase(101)}

(a) $\mathrm{Ag} \mathrm{3d}$

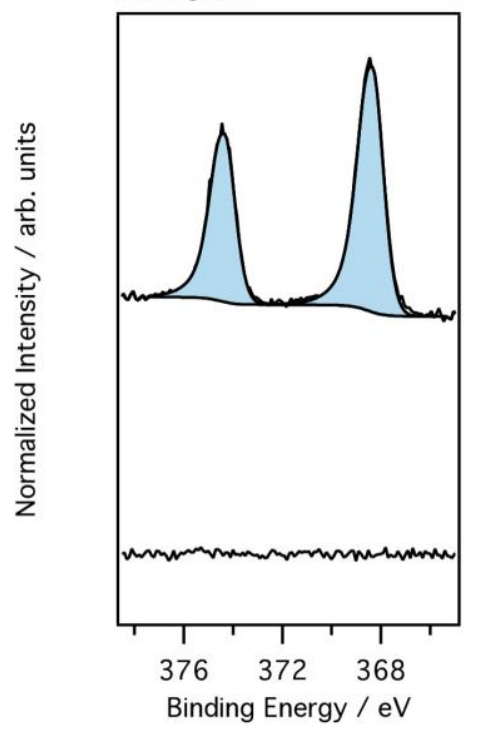

(e)

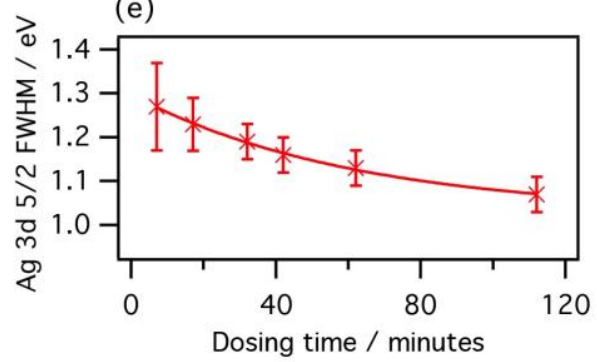

(c)

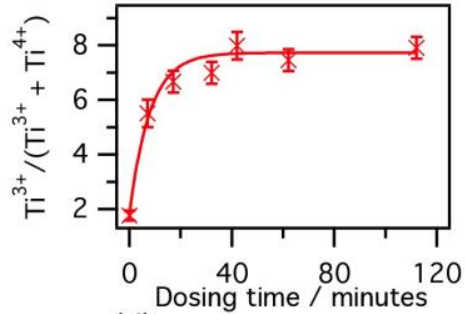

(d)

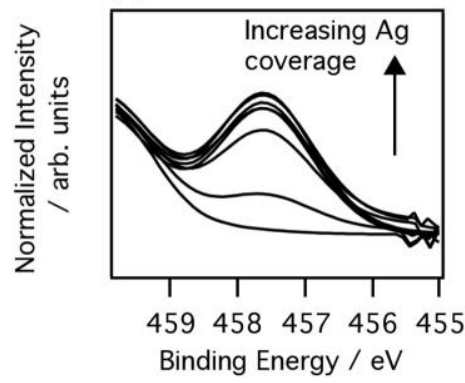

(f)

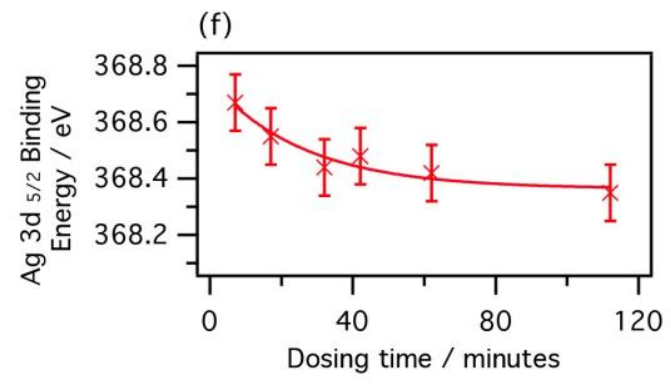

Figure 1: (a) Ag 3d XPS core-level spectra $(h v=1 \mathrm{keV})$ recorded from the anatase $\mathrm{TiO}_{2}(101)$ single crystal following $\mathrm{Ag}$ deposition for 110 minutes (top) and the clean anatase $\mathrm{TiO}_{2}(101)$ surface (bottom) (b) the corresponding Ti $2 p$ spectra with (top) and without (bottom) Ag ( $h v=1 \mathrm{keV}$ ). The spectra are normalized to the height of the $\mathrm{Ti} 2 \mathrm{p}_{3 / 2} \mathrm{Ti}^{4+}$ peak at $459.2 \mathrm{eV}$. (c) Plot of relative $\mathrm{Ti}^{3+}$ concentration vs Ag exposure. (d) Expanded view of the Ti 2p XPS core-level spectra, highlighting the increase in the $\mathrm{Ti}^{3+}$ oxidation state as $\mathrm{Ag}$ coverage is increased. (e) Plot of the variation in full width half maximum of the $\mathrm{Ag} 3 \mathrm{~d}_{5 / 2}$ peak as Ag coverage is increased. (f) Plot of the variation in binding energy of the $A g 3 d_{5 / 2}$ peak vs $A g$ coverage. 
Core level photoelectron spectra for $\mathrm{Ag} 3 \mathrm{~d}$ and $\mathrm{Ti} 2 \mathrm{p}(h v=1 \mathrm{keV})$ for the clean anatase $\mathrm{TiO}_{2}(101)$ surface and the maximum Ag coverage are shown in Figure 1 (a) and (b), respectively. A full set of $\mathrm{Ti} 2 \mathrm{p}$ and $\mathrm{Ag} 3 \mathrm{~d}$ spectra, as a function of $\mathrm{Ag}$ exposure, are shown in Figure $\mathrm{S} 1$ of the supporting information (SI). In each case, the $\mathrm{Ag}$ spectra are normalized to the peak intensity of the corresponding Ti $2 \mathrm{p}_{3 / 2}$ feature.

The Ti $2 p$ spectrum is composed of spin orbit split peaks at binding energies of 459.2 $\mathrm{eV}\left(\mathrm{Ti} 2 \mathrm{p}_{3 / 2}\right)$ and $464.9 \mathrm{eV}\left(\mathrm{Ti} 2 \mathrm{p}_{1 / 2}\right)$, consistent with $\mathrm{Ti}^{4+}$. Upon exposure to $\mathrm{Ag}$ a small shoulder appears on the lower binding energy side of the main $\mathrm{Ti} 2 \mathrm{p}_{3 / 2}$ peak, consistent with the reduction of $\mathrm{Ti}^{4+}$ to $\mathrm{Ti}^{3+}(457.7 \mathrm{eV})$, suggesting charge transfer from the $\mathrm{Ag}$ to the $\mathrm{TiO}_{2}$ surface. Figure 1 (c) and (d), show how the relative amount of $\mathrm{Ti}^{3+}$ changes as a function of $\mathrm{Ag}$ deposition. As the $\mathrm{Ag}$ coverage increases the proportion of $\mathrm{Ti}^{3+}$ also increases up to an exposure time of around 20 minutes. For deposition times of over 20 minutes the $\mathrm{Ti}^{3+}$ concentration reaches a plateau. Reduction of titania has been reported following deposition of various metal clusters, including $\mathrm{Co}, \mathrm{Ni}$, and $\mathrm{Pt} \cdot{ }^{4,10,39} \mathrm{Au}$, on the other hand has been shown to remove $\mathrm{Ti}^{3+}$ from the surface ${ }^{40}$. The degree of reduction of $\mathrm{Ti}$ is characteristic of the relative strength of the interaction between the metal clusters and the titania surface. ${ }^{4,10}$ At saturation we find a $6 \%$ increase in the concentration of $\mathrm{Ti}^{3+}$ compared to the clean surface. In contrast, following deposition of silver clusters on the rutile $\mathrm{TiO}_{2}$ (110) surface, no reduction was reported. This suggests that the interfacial interaction of $\mathrm{Ag}$ with the anatase (101) face is stronger than with the rutile (110) surface of $\mathrm{TiO}_{2} \cdot{ }^{1}$ 
The $\mathrm{Ag} 3 \mathrm{~d}$ spectrum recorded from this surface is composed of spin-orbit peaks at binding energies of $368.7 \mathrm{eV}\left(\mathrm{Ag} 3 \mathrm{~d}_{5 / 2}\right)$ and $374.7 \mathrm{eV}\left(\mathrm{Ag} \mathrm{3} \mathrm{d}_{3 / 2}\right)$. These binding energies are consistent with $\mathrm{Ag}$ in the metallic state. ${ }^{24}$ As the surface coverage of $\mathrm{Ag}$ on $\mathrm{TiO}_{2}$ increases, a small downward shift in $\mathrm{BE}$ of the $\mathrm{Ag} 3 \mathrm{~d}$ peak is observed, as shown in Figure 1 (f). Similar shifts have been seen with $\mathrm{Ag}$ and other transition metal clusters on various metal oxide surfaces including the rutile $\mathrm{TiO}_{2}(110)$ surface and are indicative of an increasing cluster size. ${ }^{1,41-44}$ Figure 1 (e) illustrates the decrease in Full Width Half Maximum (FWHM) as coverage is increased and is further evidence of an increasing cluster size. ${ }^{1,42,44}$ Initial and final state effects will occur to varying degrees for Ag clusters of different sizes. This then produces a distribution of BEs manifested as a broadening of the peak. This broadening effect becomes less prominent as the Ag clusters become more bulk like. ${ }^{1}$ Peak broadening for small cluster sizes may also be a result of the shortened lifetime of the core hole, due to faster relaxation times. ${ }^{44}$

STM images for the as-prepared anatase $\mathrm{TiO}_{2}(101)(1 \times 1)$ surface and three different Ag exposures, are shown in Figure 2 (a) - (d). The characteristic trapezoidal island structures of anatase(101) are clearly observed in Figure 2 (a), separated by monatomic steps of height around $3 \AA$. Assuming that the clusters adopt a FCC packing structure ${ }^{45}$ with inter-atomic $\mathrm{Ag}-\mathrm{Ag}$ distance equivalent to that of bulk $\mathrm{Ag}$, i.e. $2.9 \AA{ }^{21}$ and are hemispherical with a radius equivalent to the apparent height, it is possible to extract a qualitative estimate for the number of $\mathrm{Ag}$ atoms per cluster at exposures up to one monolayer. 
(a)

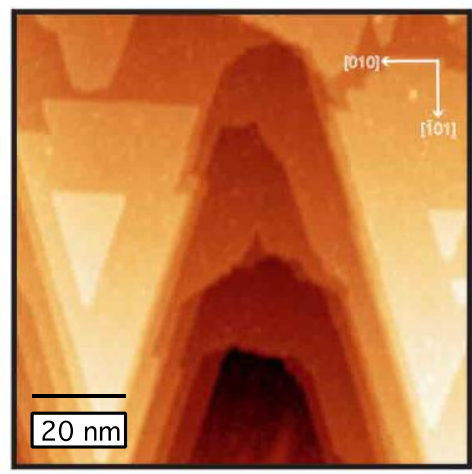

(b)

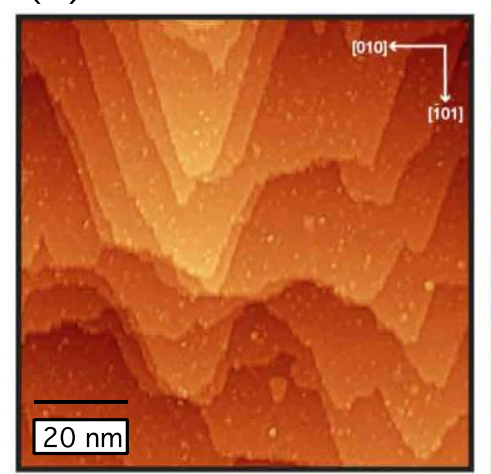

(c)

(d)
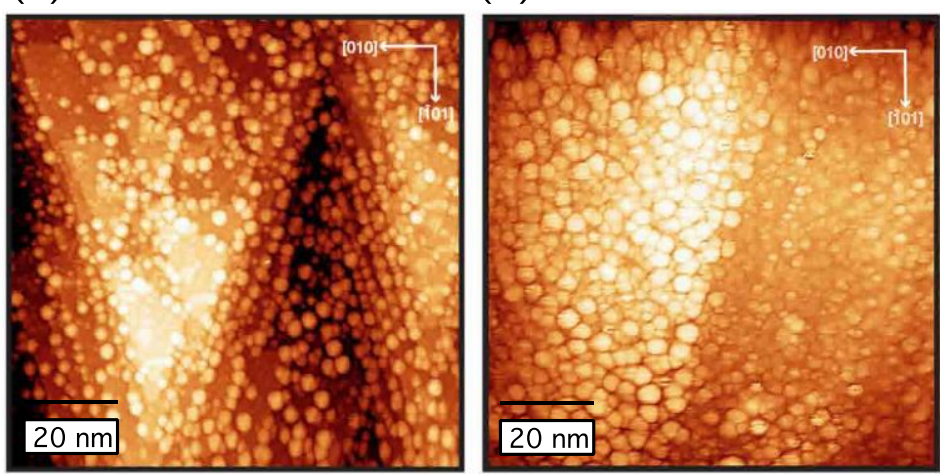

(e)

$\downarrow$

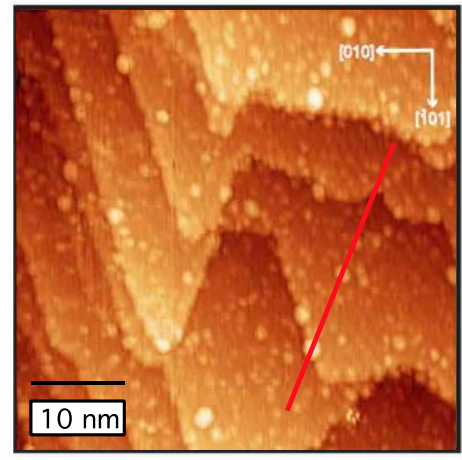

(f)

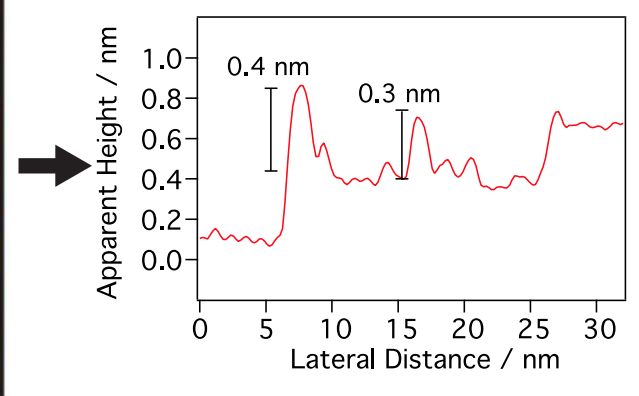

Figure 2: $100 \times 100 \mathrm{~nm}^{2}$ STM images of $(a)$ the as-prepared anatase $\mathrm{TiO}_{2}(101)(1 \times 1)$ surface and the $\mathrm{TiO}_{2}(101)(1 \times 1)$ surface after dosing Ag for (b) 1 minute (c) 5 minutes and (d) 20 minutes. (e) shows a $50 \times 50 \mathrm{~nm}^{2}$ image of surface (b) with an accompanying line profile in (f)

Figure 2 (b) shows the anatase $\mathrm{TiO}_{2}(101)$ surface following the deposition of $\mathrm{Ag}$ on the anatase $\mathrm{TiO}_{2}(101)$ surface for 1 minute. Bright protrusions are assumed to be individual atoms of $\mathrm{Ag}$ with a height of $\sim 0.2 \mathrm{~nm}$ and an average lateral diameter of 
$1.2 \mathrm{~nm}$. At the lowest coverage there appears to be no preferential adsorption site for the Ag atoms, although at larger magnification as shown in Figure 2 (e), the formation of some larger clusters, particularly at step edges, is observed (56 \% of clusters $>1.5 \mathrm{~nm}$ exist on step edges). These clusters appear to straddle the steps i.e. they are located partly on both the upper and lower terraces and have been calculated to contain up to $8 \mathrm{Ag}$ atoms. A few larger clusters are also seen on the terraces, which we assume to nucleate at surface 0 -vacancies. Figure 2 (f) contains a line profile showing the formation of a cluster straddling a step edge (with an apparent height, measured from the top of the step, of $0.4 \mathrm{~nm}$ ) and on a terrace (with an apparent height of $0.3 \mathrm{~nm}$ ).

Figure 2 (c) shows an image recorded following 5 minutes of $\mathrm{Ag}$ deposition. At this coverage the step edges are almost completely saturated with $\mathrm{Ag}$ clusters (65\% of all 'large' clusters can be seen occupying step edges) and individual Ag atoms can no longer be resolved. At this coverage a number of clusters are observed on the terraces. This coverage corresponds roughly to $1 \mathrm{ML} \mathrm{Ag}$ by comparison to deposition on the rutile (110) surface. ${ }^{46}$ Patches of bare substrate are still visible at this coverage. The clusters have an average height of $0.7 \mathrm{~nm}$ with an average lateral cluster diameter of $2.4 \mathrm{~nm}$, which corresponds to approximately $3 \mathrm{Ag}$ atomic layers and a total of 40 atoms of silver per cluster. Looking at the lateral height of the largest clusters we find a range of between 5 and $100 \mathrm{Ag}$ atoms per cluster. The 3D growth mode observed here has been attributed to the low bonding strength of $\mathrm{Ag}$ O compared to $\mathrm{Ti}-\mathrm{O}$ and also the higher free surface energy of $\mathrm{Ag}$ compared to the oxide substrate. ${ }^{47}$ It has been suggested that on the rutile $\mathrm{TiO}_{2}(110)$ surface, $\mathrm{Ag}$ 
atoms remain highly mobile and diffuse across the surface until they reach a step edge. ${ }^{46}$ Figure 2 (d) shows an image following the exposure of the anatase $\mathrm{TiO}_{2}(101)$ surface to the Ag source for 20 minutes. At this point the substrate surface is no longer visible, but the Ag still exists as nanoclusters. A measure of cluster diameters gives a mean $\mathrm{Ag}$ cluster diameter of $3.8 \mathrm{~nm}$. For this coverage an accurate height above the $\mathrm{TiO}_{2}$ surface, and therefore the number of atoms per cluster, cannot be readily extracted due to the fact that the clusters are too closely packed to measure the height from the clean surface.

(a)

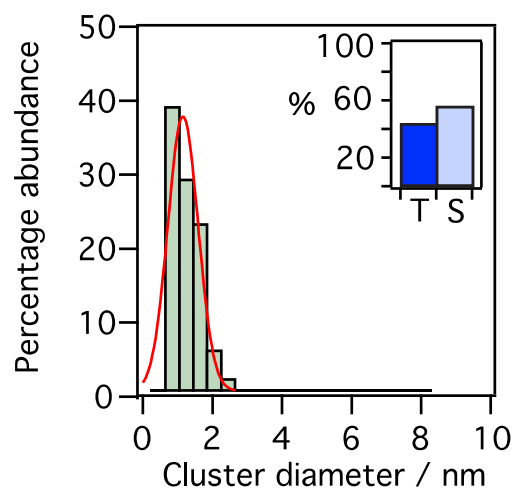

(b)

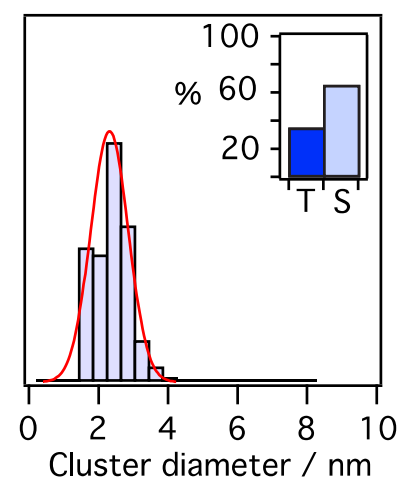

(c)

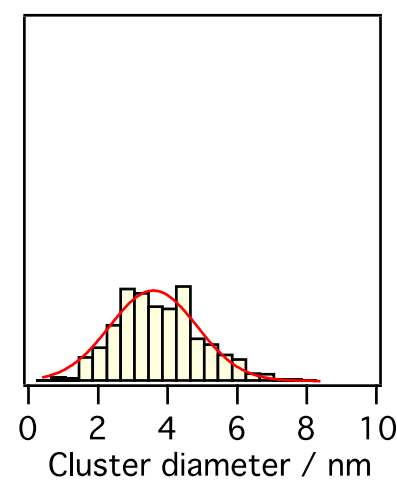

Figure 3: Histograms detailing the average diameter of the clusters populating the surface after dosing Ag for (a) 1 minute (average diameter of $1.2 \mathrm{~nm}$ with a standard deviation of 0.5 ) - inset relative percentage of larger clusters $(>1.5 \mathrm{~nm}$ ) that reside on terraces $(\mathrm{T})$ or step edges $(\mathrm{S})(\mathrm{b}) 5$ minutes (average diameter of $2.4 \mathrm{~nm}$ with a standard deviation of 0.6 ) - inset relative percentage of larger clusters $(>1.5 \mathrm{~nm})$ that reside on terraces $(T)$ or step edges $(\mathrm{S})$ and $(\mathrm{c}) 20$ minutes (average diameter of $3.8 \mathrm{~nm}$ with a standard deviation of 1.3).

The histogram plots in Figure 3 show the spread of cluster diameters for the different Ag exposures. Although tip convolution effects tend to lead to an overestimate of cluster diameters, ${ }^{21,39}$ the measurements still allow a qualitative measure of the cluster growth. The histogram plots show an increase in average 
cluster size as a function of deposition time/coverage and that the distribution of the diameters increases with a standard deviation of $1.3 \mathrm{~nm}$ at maximum coverage. The narrow range of cluster heights and diameters found for the 5 minute (ca $1 \mathrm{ML}$ ) deposition of $\mathrm{Ag}$ on anatase $\mathrm{TiO}_{2}$ is consistent with the growth of $\mathrm{Ag}$ on the rutile $\mathrm{TiO}_{2}(110)$ surface, ${ }^{1,46}$ although the average cluster height and diameter on the anatase surface are somewhat smaller. The observed 3D growth mode is as expected from surface free energies of the $\mathrm{Ag}$ and $\mathrm{TiO}_{2}$ and is common to most transition metal growth modes on metal oxide surfaces. ${ }^{47}$ On the rutile surface the average cluster heights and diameters at the equivalent coverage are 1.4 and $7.5 \mathrm{~nm}$, respectively. The observation of individual atoms at the lowest exposure studied here, and the smaller cluster sizes suggest that Ag diffusion to step edges and defect sites is much slower than on the rutile surface. For the rutile $\mathrm{TiO}_{2}(110)$ surface an increase in the surface temperature, which increases the diffusion rate, leads to larger cluster sizes. ${ }^{46}$ This slower diffusion on the anatase surface suggests a stronger interaction between $\mathrm{Ag}$ and anatase $\mathrm{TiO}_{2}$ and is consistent with the observation of charge transfer from the $\mathrm{Ag}$ to surface $\mathrm{Ti}$ ions. This growth mode also accounts for the observed initial increase and then plateau observed in the surface $\mathrm{Ti}^{3+}$ concentration in photoelectron spectra. The STM data confirm that the observed downward shift in binding energy of the $\mathrm{Ag} 3 \mathrm{~d}$ peaks is related to the cluster size, i.e. as the clusters grow, they become more metal-like until the binding energy reaches that of bulk metal. ${ }^{1,39}$ The smaller clusters observed on the anatase relative to rutile and also the charge transfer observed is likely to account for the enhanced catalytic activity of anatase relative to rutile $\mathrm{TiO}_{2}$, since for a similar $\mathrm{Ag}$ content the surface area/volume ratio of the clusters will be larger. 


\section{Reaction of $\mathrm{Ag} / \mathrm{TiO}_{2}$ with 3 mbar $\mathrm{H}_{2} \mathrm{O}$ and 1.5 mbar $\mathrm{H}_{2} \mathrm{O}+1.5 \mathrm{mbar} \mathrm{CO}$}

(a) Ti $2 p$

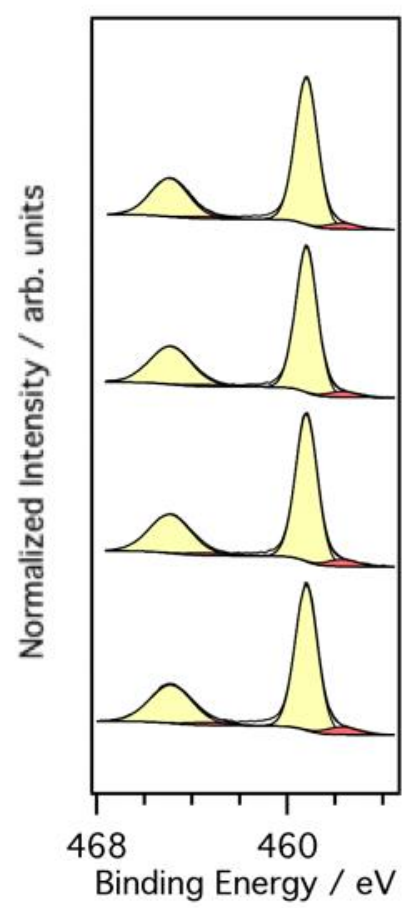

(b) Ag 3d

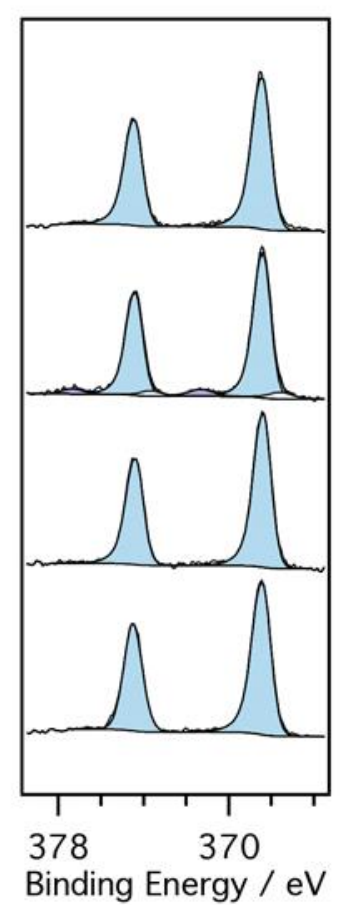

(c) $01 \mathrm{~s}$

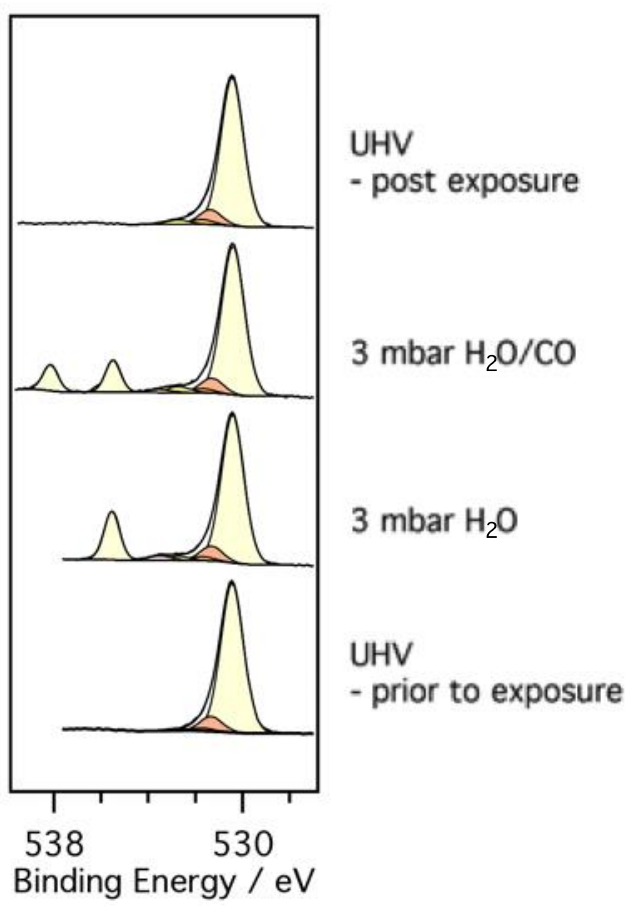

Figure 4: (a) Ag 3d and (b) O 1s core level photoelectron spectra around the high binding edge of the main oxide derived $\mathrm{O} 1 \mathrm{~s}$ peak. The full $\mathrm{O}$ 1s spectrum is shown in Figure $\mathrm{S} 2$. The spectra are recorded at $h v=1486.6 \mathrm{eV}$ under exposure to $3 \mathrm{mbar} \mathrm{H}_{2} \mathrm{O}$ and co-exposure to $1.5 \mathrm{mbar} \mathrm{H}_{2} \mathrm{O} / 1.5 \mathrm{mbar} \mathrm{CO}$.

In order to investigate the reactivity of the $\mathrm{Ag} / \mathrm{TiO}_{2}$ surface $\mathrm{Ag}$ clusters were deposited upon a freshly prepared anatase $\mathrm{TiO}_{2}(101)$ crystal for 5 minutes, corresponding to the intermediate coverage shown in the STM image in Figure $2 \mathrm{c}$. This sample was exposed to $3 \mathrm{mbar} \mathrm{H}_{2} \mathrm{O}$ followed by a mixed gas composition of $\mathrm{pH}_{2} \mathrm{O}=1.5$ mbar and $\mathrm{pCO}=1.5$ mbar, whilst XPS spectra were recorded in situ .

Exposure of the $\mathrm{Ag} / \mathrm{TiO}_{2}$ surface to a water partial pressure $\left(\mathrm{pH}_{2} \mathrm{O}\right)$ of 3 mbar has no effect on $\mathrm{Ag}$ and $\mathrm{Ti}$ core level spectra. The $\mathrm{H}_{2} \mathrm{O} / \mathrm{CO}$ mixture also has no noticeable 
effect on the Ti $2 p$ spectrum. Exposure to the mixed $\mathrm{CO} / \mathrm{H}_{2} \mathrm{O}$ gas, however, leads to the appearance of new features in the $\mathrm{Ag} 3 \mathrm{~d}$ spectrum as shown in Figure 4 (b). These occur, as spin-orbit split peaks, at binding energies of $367.6 \mathrm{eV}$ and $373.7 \mathrm{eV}$, and $371.4 \mathrm{eV}$ and $377.5 \mathrm{eV}$. The lower binding energy peaks in the Ag spectra are consistent with the oxidation of some $\mathrm{Ag}^{48}$ and have been observed following $\mathrm{CO}$ oxidation on an $\mathrm{Ag}(001)$ surface. ${ }^{49}$ This downward shift appears anomalous, since an increase in oxidation state is usually associated with an increase in binding energy for metal cations in ionic systems. Although the downward shift in binding energy of oxidized silver was first reported over 40 years ago by Schön et al. ${ }^{50}$ the origin of the shift is still unclear. Various explanations based on the initial state energy of the emitting cation have been proposed, including covalency of the Ag-O bond combined with the effect of the Madelung potential on the $\mathrm{BE}^{51}$ or a shift in the Fermi energy. ${ }^{48} \mathrm{~A}$ recent density functional theory (DFT) and high resolution core level spectroscopy study assigns the downwards shift to a final-state effect, where the core-hole is screened by s-derived states of bonding character. ${ }^{48}$ The precise oxidation state of the Ag can not be determined from these measurements, but the binding energy agrees well with the formation of $\mathrm{Ag}^{\delta+} .49$

The origin of the peaks at $371.4 \mathrm{eV}$ and $377.5 \mathrm{eV}$ is less clear. The binding energies are consistent with Ag plasmon loss peaks, but if this were the case then one would also expect to observe them on the $\mathrm{Ag}$ clusters before exposure to $\mathrm{H}_{2} \mathrm{O} / \mathrm{CO}$. The presence of these peaks, in conjunction with the lower binding energy peaks are also consistent with the presence of $\mathrm{Ag}(\mathrm{III})$ species, where they have been assigned as satellites. However, previous work suggests $\mathrm{Ag}(\mathrm{III})$ is not particularly stable in vacuum ${ }^{51}$ so this is unlikely. In addition, although the peaks appear at the same time 
as the oxide peaks the intensity is almost equivalent to that of the main oxide peaks so this too suggests these are not related to Ag (III). These higher energy features were not observed in spectra recorded from an $\mathrm{Ag}(001)$ exposed to $5 \mathrm{mbar} \mathrm{CO}$ and subjected to "post-mortem" analysis. ${ }^{49}$ Figure $4 \mathrm{~b}$ shows that removal of the $\mathrm{CO} / \mathrm{H}_{2} \mathrm{O}$ gas in order to return to UHV conditions leads to the disappearance of both sets of doublets introduced by the exposure to the gas mixture. These observations suggest that these higher binding energy peaks are associated with the interaction of CO with the Ag clusters, but their origin cannot be unambiguously determined from these data. Further work using synchrotron radiation resonant near-ambient pressure photoemission, which would allow us to carry out depth profiling by tuning the kinetic energy and emission angle of the photoemitted electrons, may prove useful in determining the origin of these peaks. Detailed density functional theory calculations would also be useful. The loss of the "new" Ag 3d related features, however, indicates that the adsorption process is transient and only occurs in the presence of relatively high pressures of $\mathrm{CO}$ at room temperature. In situ IR measurements for $\mathrm{CO}$ adsorption on $\mathrm{Ag} / \mathrm{SiO}_{2}$ catalysts have shown a similar result. ${ }^{52}$ During exposure to 26 mbar $\mathrm{CO}$, linearly adsorbed $\mathrm{Ag}^{\delta+}-\mathrm{CO}$ species were identified through the appearance of a new band. This band subsequently disappeared following evacuation of the gas cell.

The $\mathrm{O}$ 1s spectra before and after exposure to both $\mathrm{H}_{2} \mathrm{O}$ and $\mathrm{H}_{2} \mathrm{O} / \mathrm{CO}$ are composed of multiple components. An expanded view of the higher binding energy shoulder is shown in SI Figure S2. The O1s spectrum prior to exposure to $\mathrm{H}_{2} \mathrm{O}$ or $\mathrm{CO}$ is fitted with 
4 components: Two components at binding energies of $530.5 \mathrm{eV}$ and $531.4 \mathrm{eV}$, arising from $\mathrm{O}^{2-}$ in anatase $\mathrm{TiO}_{2}(101)$ and two components at $531.8 \mathrm{eV}$, and $532.7 \mathrm{eV}$, which are associated with the presence of surface defects and surface hydroxyls ${ }^{53}$. Following exposure to 3 mbar $\mathrm{H}_{2} \mathrm{O}$ and $3 \mathrm{mbar} \mathrm{H}_{2} \mathrm{O} / \mathrm{CO}$, additional peaks due to photoemission from gas phase $\mathrm{H}_{2} \mathrm{O}(535.5 \mathrm{eV})$ and gas phase $\mathrm{CO}(538.2 \mathrm{eV})$ are introduced. Upon exposure to 3 mbar $\mathrm{H}_{2} \mathrm{O}$ an increase in intensity is observed in peaks at binding energies of $531.8 \mathrm{eV}, 532.7 \mathrm{eV}$ and $533.5 \mathrm{eV}$. This observation is in agreement with our previous work studying the interaction of water with the anatase $\mathrm{TiO}_{2}(101)$ surface. The peaks are assigned to the interaction of physisorbed $\mathrm{OH}$, chemisorbed $\mathrm{OH}$ and physisorbed molecular water, respectively. ${ }^{53}$ For the $\mathrm{H}_{2} \mathrm{O} / \mathrm{CO}$ mixture, the peak at a binding energy of $532.7 \mathrm{eV}$ is seen to increase in intensity, and therefore is assigned to the adsorption of $\mathrm{CO}$ on the Ag nanoclusters. Leaving the sample for 24 hours in order to attain ultra-high vacuum conditions results in some residual oxygen species at $532.7 \mathrm{eV}$, due to chemisorbed $\mathrm{OH} .{ }^{53}$ It is, however, clear that the adsorbed molecular water peak at $533.5 \mathrm{eV}$ is lost and the peak at $532.7 \mathrm{eV}$ is reduced in intensity upon the return to UHV. The reduction in intensity of the $532.7 \mathrm{eV}$ peak is in agreement with the loss of the peaks tentatively associated with $\mathrm{CO}$ adsorption in the $\mathrm{Ag} 3 \mathrm{~d}$ spectra.

The observation of the extra features observed in the $\mathrm{Ag} 3 \mathrm{~d}$ spectra, only at higher pressure serves to show the potential of NAP-XPS in bridging the pressure gap between ultrahigh vacuum and the pressures at which "real" catalytic reactions occur. Although NAP-XPS measurements are still performed at a few orders of 
magnitude below the pressures involved in some catalytic reactions, subtle chemical changes that have hitherto been unattainable can now be resolved.

\section{Conclusions}

The nucleation and subsequent growth of $\mathrm{Ag}$ clusters on anatase $\mathrm{TiO}_{2}(101)$ have been investigated using a combination of NAP-XPS and STM. Ag growth on the anatase $\mathrm{TiO}_{2}(101)$ occurs via a 3D self-limiting growth mechanism, predominantly at step edges and at defects on terrace sites to form clusters. Reduction of $\mathrm{Ti}^{4+}$ to $\mathrm{Ti}^{3+}$ is observed for the anatase surface via charge transfer from the Ag clusters, suggesting a stronger interaction between the $\mathrm{Ag}$ nanoclusters and the anatase $\mathrm{TiO}_{2}(101)$ surface than for the rutile $\mathrm{TiO}_{2}(110)$ surface. This strong interaction leads to the formation of smaller clusters and the presence of individual $\mathrm{Ag}$ atoms at very low coverage. We also find a chemisorption reaction between a mixed $\mathrm{CO} / \mathrm{H}_{2} \mathrm{O}$ vapour mixture which indicates oxidation of $\mathrm{Ag}$ species on the clusters by reaction with $\mathrm{CO}$

to form $\mathrm{Ag}^{\delta+}-\mathrm{CO}$. This species is only observed during exposure to $\mathrm{CO} / \mathrm{H}_{2} \mathrm{O}$ at pressures achievable in a NAP system.

\section{Supporting Information}

Core level photoelectron spectra for Ag 3d and Ti $2 p$ (Figure S1); Core level NAP-XPS spectra for $\mathrm{O} 1 \mathrm{~s}$ (Figure S2); Binding energy and assignment of Ti 2p, O 1s and Ag 3d XPS core-level peaks. (Table S1)

Acknowledgements 
The authors would like to thank Alexei Preobrajenski and Nikolay Vinogradov of MAX-lab for beamline support and MAX-lab for the beamtime award. We are also grateful to EPSRC UK for support through overseas travel Grant No. EP/J015075/1. MW would like to thank EPSRC UK for award of a studentship. MA and $\mathrm{HH}$ acknowledge support of the BP ICAM.

\section{References}

(1) Luo, K.; St. Clair, T. P.; Lai, X.; Goodman, D. W. Silver Growth on $\mathrm{TiO}_{2}(110)(1 \times$ 1) and (1 × 2). J. Phys. Chem. B 2000, 104, 3050-3057.

(2) Zhang, F.; Jin, R.; Chen, J.; Shao, C.; Gao, W.; Li, L.; Guan, N. High Photocatalytic Activity and Selectivity for Nitrogen in Nitrate Reduction on $\mathrm{Ag} / \mathrm{TiO}_{2}$ Catalyst with Fine Silver Clusters. J. Catal. 2005, 232, 424-431.

(3) Puigdollers, A. R.; Schlexer, P.; Pacchioni, G. Gold and Silver Clusters on TiO 2 and $\mathrm{ZrO}_{2}$ (101) Surfaces: Role of Dispersion Forces. J. Phys. Chem. C 2015, 119, 15381-15389.

(4) Galhenage, R. P.; Yan, H.; Tenney, S. A.; Park, N.; Henkelman, G.; Albrecht, P.; Mullins, D. R.; Chen, D. A. Understanding the Nucleation and Growth of Metals on $\mathrm{TiO}_{2}$ : Co Compared to Au, Ni, and Pt. J. Phys. Chem. C 2013, 117, 7191-7201.

(5) Gates, B. C. Supported Metal Clusters: Synthesis, Structure, and Catalysis. Chem. Rev. 1995, 95, 511-522.

(6) Dinh, C.-T.; Nguyen, T.-D.; Kleitz, F.; Do, T.-O. A New Route to Size and

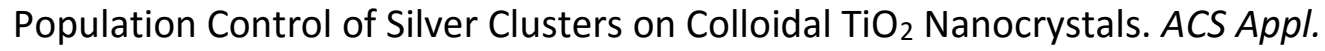
Mater. Interfaces 2011, 3, 2228-2234.

(7) Venezia, A. .; Liotta, L. .; Deganello, G.; Schay, Z.; Horváth, D.; Guczi, L. Catalytic CO Oxidation over Pumice Supported Pd-Ag Catalysts. Appl. Catal. A Gen. 2001, 211, 167-174.

(8) Bonanni, S.; Aït-Mansour, K.; Brune, H.; Harbich, W. Overcoming the Strong Metal-Support Interaction State: CO Oxidation on $\mathrm{TiO}_{2}(110)$-Supported Pt Nanoclusters. ACS Catal. 2011, 1, 385-389. 
(9) Yu, F.; Qu, Z.; Zhang, X.; Fu, Q.; Wang, Y. Investigation of CO and Formaldehyde Oxidation over Mesoporous $\mathrm{Ag} / \mathrm{CO}_{3} \mathrm{O}_{4}$ Catalysts. J. Energy Chem. 2013, 22, 845-852.

(10) Li, F. B.; Li, X. Z. The Enhancement of Photodegradation Efficiency Using Pt$\mathrm{TiO}_{2}$ Catalyst. Chemosphere 2002, 48, 1103-1111.

(11) Fu, Q.; Wagner, T. Interaction of Nanostructured Metal Overlayers with Oxide Surfaces. Surf. Sci. Rep. 2007, 62, 431-498.

(12) Chusuei, C. C.; Lai, X.; Luo, K.; Goodman, D. W. Modeling Heterogeneous Catalysts: Metal Clusters on Planar Oxide Supports. Top. Catal. 2000, 14, 7183.

(13) Ferrari, A. M.; Pacchioni, G. Metal Deposition on Oxide Surfaces: A QuantumChemical Study of the Interaction of $\mathrm{Rb}, \mathrm{Pd}$, and Ag Atoms with the Surface Vacancies of MgO. J. Phys. Chem. 1996, 100, 9032-9037.

(14) Kizuka, T.; Tanaka, N. Atomic Process of Epitaxial Growth of Gold on Magnesium Oxide Studied by Cross-Sectional Time-Resolved High-Resolution Electron Microscopy. Phys. Rev. B 1997, 56, R10079-R10088.

(15) Barbier, A.; Renaud, G.; Jupille, J. Evolution of the Cluster Shape during the Growth of Ag on MgO(001). Surf. Sci. 2000, 454-456, 979-983.

(16) Xu, C.; Oh, W. S.; Liu, G.; Kim, D. Y.; Goodman, D. W. Characterization of Metal Clusters (Pd and $\mathrm{Au}$ ) Supported on Various Metal Oxide Surfaces (MgO and $\mathrm{TiO}_{2}$ ). J. Vac. Sci. Technol. A Vacuum, Surfaces, Films. 1997, 15, 1261.

(17) Bonanni, S.; Aït-Mansour, K.; Harbich, W.; Brune, H. Effect of the $\mathrm{TiO}_{2}$ Reduction State on the Catalytic CO Oxidation on Deposited Size-Selected Pt Clusters. J. Am. Chem. Soc. 2012, 134, 3445-3450.

(18) Valden, M.; Lai, X.; Goodman, D. W. Onset of Catalytic Activity of Gold Clusters on Titania with the Appearance of Nonmetallic Properties. Science 1998, 281, 1647-1650.

(19) Chen, Y.-S.; Choi, H.; Kamat, P. V. Metal-Cluster-Sensitized Solar Cells. A New Class of Thiolated Gold Sensitizers Delivering Efficiency Greater Than 2\%. J. Am. Chem. Soc. 2013, 135, 8822-8825.

(20) Mazheika, A. S.; Bredow, T.; Matulis, V. E.; Ivashkevich, O. A. Theoretical Study of Adsorption of Ag Clusters on the Anatase $\mathrm{TiO}_{2}(100)$ Surface. J. Phys. Chem. C 2011, 115, 17368-17377.

(21) Benz, L.; Tong, X.; Kemper, P.; Lilach, Y.; Kolmakov, A.; Metiu, H.; Bowers, M. T.; Buratto, S. K. Landing of Size-Selected $\mathrm{Ag}_{n}{ }^{+}$Clusters on Single Crystal 
$\mathrm{TiO}_{2}(110)-(1 \times 1)$ Surfaces at Room Temperature. J. Chem. Phys. 2005, 122, 81102.

(22) Tong, X.; Benz, L.; Kolmakov, A.; Chrétien, S.; Metiu, H.; Buratto, S. K. The Nucleation Sites of Ag Clusters Grown by Vapor Deposition on a $\mathrm{TiO}_{2}(110)-1 \times 1$ Surface. Surf. Sci. 2005, 575, 60-68.

(23) Hirakawa, T.; Kamat, P. V. Charge Separation and Catalytic Activity of Ag@TiO Core-Shell Composite Clusters under UV-Irradiation. J. Am. Chem. Soc. 2005, 127, 3928-3934.

(24) Yang, L.; Jiang, X.; Ruan, W.; Yang, J.; Zhao, B.; Xu, W.; Lombardi, J. R. ChargeTransfer-Induced Surface-Enhanced Raman Scattering on $\mathrm{Ag}-\mathrm{TiO}_{2}$ Nanocomposites. J. Phys. Chem. C 2009, 113, 16226-16231.

(25) Dozzi, M.; Selli, E. Specific Facets-Dominated Anatase $\mathrm{TiO}_{2}$ : Fluorine-Mediated Synthesis and Photoactivity. Catalysts 2013, 3, 455-485.

(26) Ohno, T.; Sarukawa, K.; Tokieda, K.; Matsumura, M. Morphology of a TiO2 Photocatalyst (Degussa, P-25) Consisting of Anatase and Rutile Crystalline Phases. J. Catal. 2001, 203, 82-86.

(27) Barhoum, A.; Rehan, M.; Rahier, H.; Bechelany, M.; Assche, G. Van. SeedMediated Hot-Injection Synthesis of Tiny Ag Nanocrystals on Nanoscale Solid Supports and Reaction Mechanism. ACS Appl. Mater. Interfaces 2016, 8, 10551-10561.

(28) Chen, J.-J.; Wang, W.-K.; Li, W.-W.; Pei, D.-N.; Yu, H.-Q. Roles of Crystal Surface in Pt-Loaded Titania for Photocatalytic Conversion of Organic Pollutants: A First-Principle Theoretical Calculation. ACS Appl. Mater. Interfaces 2015, 7, 12671-12678.

(29) Jia, C.; Zhang, G.; Zhong, W.; Jiang, J. A First-Principle Study of Synergised $\mathrm{O}_{2}$ Activation and $\mathrm{CO}$ Oxidation by $\mathrm{Ag}$ Nanoparticles on $\mathrm{TiO}_{2}$ (101) Support. ACS Appl. Mater. Interfaces 2016, 8, 10315-10323.

(30) Chun-Ren Ke, J.; Walton, A. S.; Lewis, D. J.; Tedstone, A.; O'Brien, P.; Thomas, A. G.; Flavell, W. R.; Hagfeldt, A.; Grätzel, M.; Li, W. In Situ Investigation of Degradation at Organometal Halide Perovskite Surfaces by X-Ray Photoelectron Spectroscopy at Realistic Water Vapour Pressure. Chem. Commun. 2017, 53, 5231-5234.

(31) Haubrich, J.; Quiller, R. G.; Benz, L.; Liu, Z.; Friend, C. M. In Situ Ambient Pressure Studies of the Chemistry of $\mathrm{NO}_{2}$ and Water on Rutile $\mathrm{TiO}_{2}(110)$. Langmuir 2010, 26, 2445-2451.

(32) Rosseler, O.; Sleiman, M.; Montesinos, V. N.; Shavorskiy, A.; Keller, V.; Keller, N.; Litter, M. I.; Bluhm, H.; Salmeron, M.; Destaillats, H. Chemistry of $\mathrm{NO}_{x}$ on 
$\mathrm{TiO}_{2}$ Surfaces Studied by Ambient Pressure XPS: Products, Effect of UV Irradiation, Water, and Coadsorbed K+. J. Phys. Chem. Lett. 2013, 4, 536-541.

(33) Kondoh, H.; Toyoshima, R.; Monya, Y.; Yoshida, M.; Mase, K.; Amemiya, K.; Mun, B. S. In Situ Analysis of Catalytically Active Pd Surfaces for CO Oxidation with near Ambient Pressure XPS. Catal. Today 2016, 260, 14-20.

(34) Favaro, M.; Jeong, B.; Ross, P. N.; Yano, J.; Hussain, Z.; Liu, Z.; Crumlin, E. J. Unravelling the Electrochemical Double Layer by Direct Probing of the Solid/liquid Interface. Nat. Commun. 2016, 7, 12695.

(35) Wang, H.; Zhang, X.; Gong, F.; Zhou, G.; Wang, Z.-S. Novel Ester-Functionalized Solid-State Electrolyte for Highly Efficient All-Solid-State Dye-Sensitized Solar Cells. Adv. Mater. 2012, 24, 121-124.

(36) Horcas, I.; Fernández, R.; Gómez-Rodríguez, J. M.; Colchero, J.; GómezHerrero, J.; Baro, A. M. WSXM: A Software for Scanning Probe Microscopy and a Tool for Nanotechnology. Rev. Sci. Instrum. 2007, 78, 013705.

(37) Nečas, D.; Klapetek, P. Gwyddion: An Open-Source Software for SPM Data Analysis. Cent. Eur. J. Phys. 2012, 10, 181-188.

(38) Fairley, N. CasaXPS Manual 2.3.15 Introduction to XPS and AES; Casa Software, 2009.

(39) Tenney, S. A.; He, W.; Ratliff, J. S.; Mullins, D. R.; Chen, D. A. Characterization of Pt-Au and Ni-Au Clusters on $\mathrm{TiO}_{2}$ (110). Top. Catal. 2011, 54, 42-55.

(40) Chen, M.; Goodman, D. W. Catalytically Active Gold: From Nanoparticles to Ultrathin Films. Acc. Chem. Res. 2006, 39, 739-746.

(41) Yang, Z.; Wu, R. Origin of Positive Core-Level Shifts in Au Clusters on Oxides. Phys. Rev. B 2003, 67, 081403.

(42) St.Clair, T. P.; Goodman, D. W. Metal Nanoclusters Supported on Metal Oxide Thin Films: Bridging the Materials Gap. Top. Catal. 2000, 13, 5-19.

(43) Sexton, B.; Hughes, A. E.; Foger, K. XPS Investigation of Strong Metal-Support Interactions on Group Illa-Va Oxides. J. Catal. 1982, 77 (1), 85-93.

(44) Tao, J. G.; Pan, J. S.; Huan, C. H. A.; Zhang, Z.; Chai, J. W.; Wang, S. J. Origin of XPS Binding Energy Shifts in Ni Clusters and Atoms on Rutile $\mathrm{TiO}_{2}$ Surfaces. Surf. Sci. 2008, 602, 2769-2773.

(45) Harfenist, S. A.; Wang, Z. L.; Alvarez, M. M.; Vezmar, I.; Whetten, R. L. Highly Oriented Molecular Ag Nanocrystal Arrays. J. Phys. Chem. 1996, 100, 1390413910. 
(46) Chen, D. A.; Bartelt, M. C.; Seutter, S. M.; McCarty, K. F. Small, Uniform, and Thermally Stable Silver Particles on $\mathrm{TiO}_{2}(110)-(1 \times 1)$. Surf. Sci. 2000, 464, L708L714.

(47) Bäumer, M.; Freund, H. J. Metal Deposits on Well-Ordered Oxide Films. Prog. Surf. Sci. 1999, 61, 127-198.

(48) Grönbeck, H.; Klacar, S.; Martin, N. M.; Hellman, A.; Lundgren, E.; Andersen, J. N. Mechanism for Reversed Photoemission Core-Level Shifts of Oxidized Ag. Phys. Rev. B 2012, 85, 115445.

(49) Ringleb, F.; Fujimori, Y.; Brown, M. A.; Kaden, W. E.; Calaza, F.; Kuhlenbeck, H.; Sterrer, M.; Freund, H.-J. The Role of Exposed Silver in CO Oxidation over $\mathrm{MgO}(001) / \mathrm{Ag}(001)$ Thin Films. Catal. Today 2015, 240, 206-213.

(50) Schön, G.; Tummavuori, J.; Lindström, B.; Enzell, C. R.; Enzell, C. R.; Swahn, C.G. ESCA Studies of Ag, Ag2O and AgO. Acta Chem. Scand. 1973, 27, 26232633.

(51) Kaspar, T. C.; Droubay, T.; Chambers, S. A.; Bagus, P. S. Spectroscopic Evidence for $\mathrm{Ag}(\mathrm{III})$ in Highly Oxidized Silver Films by X-Ray Photoelectron Spectroscopy. J. Phys. Chem. C 2010, 114, 21562-21571.

(52) Qu, Z.; Zhou, S.; Wu, W.; Li, C.; Bao, X. CO Adsorption and Correlation between CO Surface Coverage and Activity/selectivity of Preferential CO Oxidation over Supported Ag Catalyst: An in Situ FTIR Study. Catal. Letters 2005, 101, 21-26.

(53) Jackman, M. J.; Thomas, A. G.; Muryn, C. Photoelectron Spectroscopy Study of Stoichiometric and Reduced Anatase $\mathrm{TiO}_{2}(101)$ Surfaces: The Effect of Subsurface Defects on Water Adsorption at Near-Ambient Pressures. J. Phys. Chem. C 2015, 119, 13682-13690. 
TOC Graphic

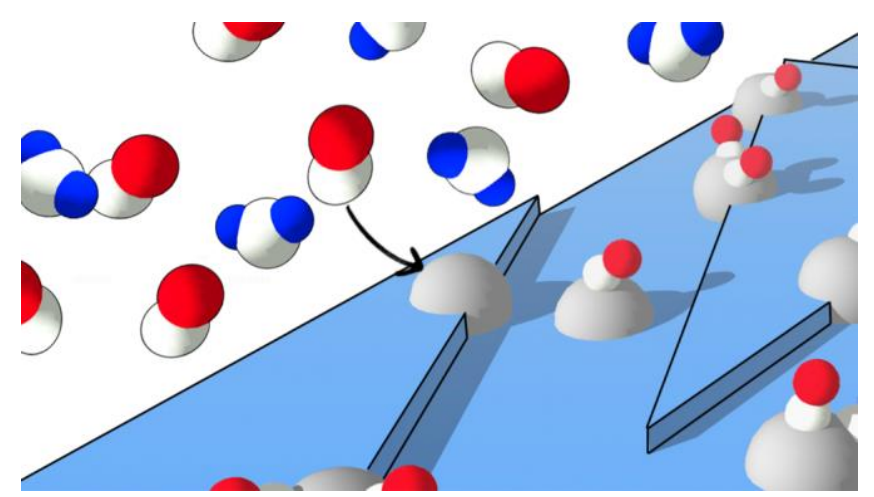

